\title{
Content And Services For The New Digital TV Environment
}

\author{
John Carey
}

\begin{abstract}
Content, not technology, will encourage the widespread adoption of digital television. A broad scope of new channels and services are possible in a digital TV environment. These include high definition television, video-on-demand movies, theme channels, multicasting or the distribution of the same content on different channels at different times, Internet content on TV sets, video segments on personal computers, interactive shopping and games, and program guides for hundreds of channels. There are many opportunities for more and better content but there are also uncertainties about the business models for digital TV and concerns about who will control content.
\end{abstract}

Keywords: digital TV, HDTV, interactive TV, multimedia

\section{Introduction}

An award-winning TV commercial for Barney's, a clothing store in New York, depicted the owner, Barney, as a young boy surrounded by friends. As the camera panned across the boys, each described his intended career - doctor, policeman and so forth. When the camera stopped on Barney, he said, "you're all going to need clothes." Content is the clothing in the new digital TV environment. It is often taken for granted in heated debates over standards, competition and delivery platforms for digital TV. However, content not technology will drive the adoption of digital TV.

The conversion to a digital environment in satellite transmission, cable, telephone systems, broadcast TV and wireless microwave is moving forward with a typical pattern of starts, stops, and near-term diversions. However, the direction - if not the timetable - is clear: television is becoming a digital medium. Some groups have adopted digital technology at a strong pace, e.g., satellite system operators and service providers. Other 
groups such as terrestrial broadcasters, cable systems and telephone companies have conducted many trials and, in some cases, announced plans for the broad diffusion of digital services during 1998.

Under a slow or quick pace for the diffusion of digital TV, the question remains: what content and services will be offered? In addressing this issue, it is useful to examine a range of content and service offerings: high-end and low-end as well as near-term and mid-term. It is also important to recognize that many new services are likely to emerge through a process of creative experimentation after digital technology is in the marketplace. Unanticipated and unplanned services are often the most exciting for consumers and the most profitable for content providers. However, it is very difficult to predict what these services might be or who will offer them.

\section{High Definition Television (HDTV)}

The impetus for developing digital television, in the U.S. and Europe, was to provide a better system for HDTV ${ }^{1}$. However, the interest of U.S. and European broadcasters in providing HDTV and their timetable for moving forward have become cloudy. Japan implemented an analog version of HDTV (Hi-Vision) delivered via direct broadcast satellite (DBS) in the early 1990s but it has not been widely adopted. They have discussed moving over to digital HDTV by the year 2000 but the support for such a system is unclear $^{2}$.

The lukewarm response to HDTV by broadcasters and other service providers relates to better revenue opportunities they perceive in different uses for digital technology along with the high cost of converting to digital $\mathrm{HDTV}^{3}$. Consumer demand for HDTV is largely 
untested. It is noteworthy that so much of the discussion about digital TV has shifted away from HDTV and towards other applications such as increasing the number of channels in digital systems. From a content perspective, HDTV is in good shape. Unlike some other applications for digital TV, there is a great deal of content available for HDTV. Virtually all theatrically-released movies are shot in $35 \mathrm{~mm}$ film and therefore can be converted to HDTV. Live sports can be transmitted through HDTV and much regular television programming is available for HDTV (i.e., all programs shot in $35 \mathrm{~mm}$ film, super $16 \mathrm{~mm}$ film or in high-definition video). It is even possible to improve the effective resolution of older video programming through special processing and thereby render it more appealing in an HDTV environment ${ }^{4}$.

The appeal of HDTV for consumers will be in a context of viewing programs on large TV sets. With 20 or 25 inch sets, there is little noticable difference between HDTV and normal NTSC or PAL TV pictures. Similarly, HDTV does not have sufficient resolution to replace $35 \mathrm{~mm}$ film in theatres and very little interest has been shown in HDTV as a replacement for movie house projection in spite of heavy promotion by HDTV proponents $^{5}$. However, in 40 to 80 inch TV sets, HDTV has a distinct advantage over existing TV standards. The question is whether television system operators will offer enough HDTV programming to encourage consumers to purchase new TV sets. 


\section{Near-Term Digital Services}

The new digital environment will, in effect, create more capacity for content. This in turn will enable many new services that build directly upon existing content and distribution patterns. For example, channels that cannot currently find distribution in broadcast, cable or satellite environments could be carried in the new digital environment. Many of these will target specific niche groups such as people who enjoy fishing, travel, golf or cooking. The modest audience for these channels was insufficient to compete for shelf space in limited-capacity cable or broadcast environments. Some critics have argued that the proliferation of channels will lead to banal, micro-niche channels such as The Dental Hygiene Network, Homeopath TV or The Fly Fishing Channel ${ }^{6}$. However, many attractive new channels as well as existing local channels are available for distribution in the new digital environment. These include cultural offerings such as concerts, regional sports networks and ethnic programming in many different languages ${ }^{7}$.

Many of the new digital channels provide a re-packaging of existing channels into theme services. For example, the Discovery Channel has created four theme services from

its existing content: Kids; Science; Civilization; and, Travel and Living ${ }^{8}$. ARD in Germany and the BBC in the U.K. have both created theme channels ${ }^{9}$. In the U.S., A\&E, Disney, Lifetime, MTV and PBS are among those who have created or are planning to offer theme services $^{10}{ }^{11}$.

In addition, the digital TV environment is being used for multicasting or the retransmission of content on multiple channels with different schedules so that content is available more conveniently. $\mathrm{HBO}$ and Showtime are among those offering multicast channels. Other uses for extra capacity include additional pay-per-view channels and 
special packages of content such as all professional football games in a given season. Satellite services in Europe and the U.S. offer seasonal sports packages. Some of these offerings (e.g., theme channels) will provide new revenue streams while others such as multicasting may increase viewer satisfaction with a service and thereby reduce churn (i.e., the number of subscribers who cancel pay service).

An important issue associated with extending existing content into new digital environments is the ownership and control of programming, especially sports. One of the early concerns raised is that those who control the rights to sporting events and other highly desired programming may restrict the distribution of that content in order to provide a competitive advantage to one type of carrier such as satellite or cable ${ }^{12}$.

\section{Extending Current Trends In The New Environment}

The digital environment will provide an opportunity to extend current trends from the analogue environment. For example, the digital environment will provide an opportunity to offer more audio services, as an alternative to radio or compact discs, e.g., WorldDAB in Europe along with TCI and Bell South Digital Wireless in the U.S. It may also be used to offer several audio tracks for programming, each in a different language, thereby extending current closed-captioning systems into more natural audio modes. Further, the digital environment can support an improvement in the quality of audio for TV programs. This will require better speakers attached to TV sets along with higher quality audio signals in the TV transmission. Curiously, research by Russ Neuman has demonstrated that improved audio quality accompanying a TV program can lead viewers to feel that the 
video image has a higher resolution ${ }^{13}$. In this sense, improved audio might provide a cheap way to improve the perceived resolution of video.

Digital systems with 100 or more channels will require new ways to navigate among the content offerings. Program guides are offered on nearly all of the new digital systems. These allow viewers to search for programs by content category, time of day, text descriptions about the channel or program and to place electronic markers next to favorite programs or channels. A number of interesting economic and policy issues have arisen or will soon develop around program guides. First, the frequent use of program guides by viewers may help them to become valuable advertising venues, much as search engines and Web service provider home pages have attracted much advertising on the Internet because so much traffic passes through them. Second, program guides could be used to steer viewers towards some programs and away from others, to the benefit of channels offered by the parent company of the program guide. It also remains to be seen if any digital system operators will imitate the cable systems offered in many hotels, which display the program guide as a default channel whenever the TV is turned on. In simple terms, will program guides serve viewers or will they serve system operators?

Program guides can provide potentially helpful mechanisms for parents to control what their children watch. However, early parental control software in program guides has not been used by many parents. If the software provides good security, many parents find it too complex to use. If the software is easy to use, children quickly figure out ways to circumnavigate it.

Some of the most interesting changes in the new digital environment may result from side effects of "going digital." For example, the new digital environment will encourage 
many viewers to purchase larger TV sets in order to realize the benefits of better pictures. Larger TV screens, in turn, will provide an opportunity for programmers to address some of their current problems. One significant issue faced by programmers is the tendency of some viewers to change channels when a commercial comes on ${ }^{14}$. This is especially prevalent in large channel TV systems that offer viewers so many choices. One way to entice viewers to stay on a channel during commercials is to provide some content on part of the screen while the commercial plays, much as a newspaper provides both advertising and content on the same page. A few channels, notably the Bloomberg business channel, are currently employing this model. Others who make some use of this technique include CNBC, CNN Headline News and ESPN ${ }^{15}$. A newspaper model of content and ads on the same screen is easier to implement in a digital environment with larger screens and many "windows" that can hold different forms of content or advertising. It may also appeal to so-called "multi-taskers" or people who like to do many things at the same time.

The digital environment - simply because it is new - may allow programmers to renegotiate their relationship with viewers and make changes that might cause a firestorm in the current marketplace. Placing ads over content is one example of re-negotiating the relationship between programmers and viewers. Other examples are likely to emerge in the marketplace and are therefore unpredictable. Viewer responses to these changes, whether passive acceptance or protests, are also unpredictable.

Many consumers like to talk about television programs. For example, it is not uncommon for teenagers to call each other on the telephone as they are watching TV and to discuss the plot, characters, etc. In a digital environment, it will be possible for these conversations to take place in a window on the TV screen as viewers in different 
households type comments about what they are seeing. MTV tried an experiment called "MTV Yackline" in which viewers of music videos could type comments about the program through an online service. The typed comments were then superimposed at the bottom of the TV picture for all viewers to see. The experiment failed because many people did not want to see the comments, some of which were inane or obscene. However, in a digital environment it is possible for such comments to be seen only be those who wish to view them. Further, chat rooms can be created for groups of friends, who would be the only ones to see the comments. It remains unclear whether this or other forms of communications will become popular in the digital TV environment, as they have on the Internet.

\section{High-End And Longer-Term Services}

Beyond the near-term additions and changes, what new content will be tried experimentally or offered as regular services in the digital environment? New services in the digital pipeline may be grouped into a few categories. First, movies and television programs can be offered on-demand so that consumers see the content whenever they wish and, in some cases, with the same control over content that they have now with a VCR, e.g., stop, rewind, fast forward, etc.

These video-on-demand services (VOD) have been tested in a number of settings. In Europe, trials have been conducted by British Telecom in the U.K., Telenor in Norway, and Telia in Sweden, among others ${ }^{16}$. In the U.S., trials have been conducted by Bell Atlantic in Virginia, Cablevision in New York, and TCI in Denver, among others ${ }^{17}$. Consumer reactions to the services have generally been positive. Further, consumers with 
VOD have purchased more movies than comparable homes with pay-per-view $(\mathrm{PPV})^{18}$. A VOD trial in Japan had similar results ${ }^{19}$. A major question surrounding VOD is whether the service can be provided at a cost for the provider and a price for the consumer that is acceptable. Some argue that VOD is not economically feasible. This was a conclusion reached by those who conducted the VOD trial in Japan. Others argue that the costs for providers are coming down and that it will be feasible in the near future. Among the critical economic issues are the cost to digitize video and the cost as well as capacity of video servers that store movies or TV programs. The costs for both of these VOD components have been reduced sharply over the past few years ${ }^{20}$. Further, some VOD service providers are offering turnkey packages of VOD technology and content that appear to be more attractive to system operators ${ }^{21}$.

VOD technology can also be used to time-shift programming, e.g., a six o'clock news program can be made available to viewers at any point later in the same evening or a Monday night situation comedy program can be made available throughout the week. These services have been offered at lower price points than movies, e.g., 50 cents to one dollar for a one hour TV program. While this application of VOD technology duplicates what households can do with a VCR (i.e. time shift) it may appeal to those who are pressed for time and who are willing to pay for convenience.

One alternative to VOD is NVOD (near video-on-demand). In an NVOD service, several movies are transmitted each on four or five separate digital channels. The start times for a given movie are staggered every 10 to 15 minutes. In this way, a viewer can begin watching any movie within a relatively short time, or, "nearly on demand". An NVOD system for 10 movies requires 40 to 50 channels. Many satellite operators provide 
NVOD services, e.g., BSkyB and DirecTV. NVOD, like VOD, has produced higher buy rates compared to $\mathrm{PPV}^{22}$. There is much debate about the relative appeal and economic advantages of VOD versus NVOD.

Interactive television will be possible in digital environments where there is a return path from the home, school or business to the transmission source, e.g., via two-way cable, a telephone link or even a return path by radio transmission. Interactive TV for consumers was tested in the 1980s, e.g., in Biaritz, France by the French PTT, in Columbus, Ohio by Warner Amex and in Higashi Ikoma, Japan by the Hi-Ovis consortium, and found to be too expensive as well as technically difficult ${ }^{23}$. More recently, it has been tested by British Telecom in Ipswich, Colchester and in their Westminster Cable system, by Deutsche Telekom in Berlin and Nuremberg, by Telia in Jarlaberg, Stockholm, by Bell Atlantic in Dover Township, New Jersey and by Time Warner in Orlando, Florida, among others. The results were mixed. Users generally liked the services but the costs of the technology as well as content were too high $^{24}$. There is a continuing debate about the economic feasibility of high-end interactive television in the near term. The budget for a high-end interactive TV program, where most or all of the interactive elements are video, can be three or four times the budget for a linear TV program. If the budget for a major broadcast channel is one billion dollars per year, then the cost of an interactive video channel could approach three or four billion dollars. How can this cost be justified when the early audience for interactive television will, inevitably, be limited?

Simpler versions of interactive TV that mix interactive text over one-way TV or which provide interactive still images and sound may provide a path of evolution toward full 
interactive video. Further, these "economy model" forms of interactive TV are well suited to applications such as home shopping, banking and some forms of interactive games. British Interactive Broadcasting plans to test a number of these services in 1998, using satellite transmission. In addition, interactive video for education and business meetings (also called videoconferencing) has been used successfully in many settings $\mathrm{s}^{25}$.

\section{Digital Video For The PC And The Internet For TV}

The digital environment can provide video services for the personal computer such as channels of business-related video that are displayed in a window on a PC monitor. Among the challenges for these "video streaming" services are the low bandwidth that connects most PCs to the Web and competing proprietary systems that require users to obtain different software for specific services that are offered ${ }^{26}$. For this reason, the business market with its generally higher access speed to the Internet and greater technical support in the workplace, may be developed before the consumer market. SES/ASTRA launched Astra-Net in late1997 to provide high-speed data and video for business PC users in Europe. DirecPC began a similar satellite-to-PC service in the U.S. during 1997 for both consumers and businesses. In addition, CNN Interactive offers video clips for PC users over a high-speed cable data service, @Home.

Several companies offer Web services that can be displayed on regular television sets. Some of these include multimedia or video content that can be downloaded to a set-top box for display later; others allow users to make video telephone calls, e.g., Sega and NextLevel allow subscribers to use a regular camcorder attached to their set-top box for video phone calls ${ }^{27}$. In some cases the Web content comes over a telephone line and is 
then displayed on a TV set. In other cases, the content is transmitted with the TV signal and pulled out of the data stream by a set-top box, thereby eliminating the need for a telephone line or modem. WorldGate and Wink Communications provide text services that overlay TV programming in the U.S; OpenTV provides a similar service in Europe. Content can be completely separate from the TV program and displayed on a full screen by itself or it can be related to the TV program and displayed in a box on the screen over the TV picture, e.g., a viewer can call-up sports statistics from the data stream and have them displayed over the video of the sports event. In yet another variation, WebTV allows viewers to browse the Internet in a box that is superimposed over any TV program. In some ways, these services resemble teletext that has been widely adopted in many European countries $^{28}$.

\section{Hybrids}

Many content applications are possible in a digital environment. These include programs that are offered with different levels of resolution (will viewers pay more for the higher resolutions?), channels with and without ads (viewers might pay for content without ads and receive the same content with ads for free), special channels for public locations such as airports, and, private channels for corporate or government offices as well as schools that are geographically dispersed. Further, advances in digital compression have made it possible to transmit a large number of digital channels (up to 20) in the same space that one analogue channel can be transmitted. This makes private channels for education, government offices or even a supermarket chain more feasible. Several state governments in the U.S. working with local public broadcasting groups, e.g., in Kentucky, 
Mississippi, Nebraska and South Carolina, have built large digital television networks delivered via a combination of satellite, microwave, cable and/or telephone lines. These digital networks provide education services to schools as well as training and data transfer for government offices.

Many other options are possible and many more will be discovered once digital technology is widely used in the marketplace. For example, one channel could be split into two channels instantaneously to accommodate unusual circumstances. This might occur during an important breaking news story: instead of interrupting the regular broadcast for news, a station could continue its regular programming service and add a second feed of news for those who want it. It is also possible to transmit more video information than can be displayed on a TV set, e.g., a much wider picture, and let each viewer manipulate the video information by panning left or right as well as by zooming in on the picture. The technology to enable this has been developed by two groups in the U.S.: Bellcore and the Center for Telecommunications Research at Columbia University.

Kirch's DF1 digital service in Germany has developed a hybrid interactive application in which they take multiple camera feeds from a sporting event and place each feed on a separate digital channel. Viewers can become directors by moving back and forth among the channels and choosing different camera angles for the game. Videoway offered a similar service in Montreal, Canada and ACTV is developing such a service in the U.S ${ }^{29}$.

GTE's Mainstreet service and The Interactive Channel, both based in the U.S., offer still frames with photographs, graphics and text along with audio in an interactive mode. These services are less expensive to provide than full motion video. They can also be combined with Web services that are displayed on the television set. GTE has reported 
that games have been the most popular content on its Mainstreet interactive cable service in California and Florida, e.g., playing bingo against neighbors or trying to compete with contestants on quiz shows by answering the questions first ${ }^{30}$.

Another hybrid application of digital technology is the insertion of advertising in live video programs such as television sports. Currently, sports stadiums sell space for advertising on billboards that surround the playing field. With digital insertion, advertising can be superimposed anywhere in the stadium, including on the grass. People at the live event do not see the ads, but viewers at home do. This system is under development in France, Israel and the U.S. It lets the broadcaster change the inserted ads at any point and thereby sell more ads. The technology may become contentious if broadcasters superimpose a digital ad over an advertising banner that has been sold by the owners of a sports stadium. Digital insertion also opens up a potentially perilous door for changing the reality that is perceived by viewers. For example, it would be easy in a newscast to digitally change the wording on banners at a political rally or add a person to a scene who is not actually at the scene.

\section{Discussion}

Much has been learned in the trials to date about the feasibility of these new services, but much remains to be learned. For example, there is no clear answer yet in the debate over personal computers versus TV sets as the terminal of choice for digital services. Both are currently used and both are likely to be around for the foreseeable future. The widespread testing of new digital services throughout Europe, the U.S. and Asia also raises a question of sharing what has been learned. In addition to the organizations 
discussed earlier, testing of new digital services has been conducted by groups such as AT\&T, EchoStar and Microsoft in the U.S., along with Telecom Italia and Telepiu' in Italy, Tele Riviera in Nice, France, Via Digital in Spain and Cable Link in a suburb of Dublin, Ireland, among others. The research conducted about these trials is typically considered proprietary and therefore not shared. However, this often means that each new group repeats the same mistakes as earlier groups. It would be helpful to the development of digital broadcasting if more research findings were shared. In addition, there are research findings about earlier trials of services such as interactive television that are available but not widely known or disseminated.

\section{Content and Services}

Content in the early digital environment of 1996 - 1998 has included a heavy emphasis on movies and sports. Other applications that are being tested or offered include shopping, banking, education, games and news. It remains unclear how many and what kind of micro-niche services will be economically viable. For those who are concerned that narrowcasting will be taken to ridiculous extremes, it is worth noting that among the first specialized cable channels in the U.S. was a "Clock Channel." In the 1950s and 1960s, some cable operators with an extra channel, directed a camera on a wall clock and transmitted the time 24 hours a day. However, a greater concern may lie not in silly channels but sleazy ones. Whenever new distribution channels become available, an opportunity emerges for content such as pornography and programming with extreme violence. The digital environment is no exception. Parental control software is likely to be inneffective in blocking such content. A better option may be to switch from active 
blocking of content to active authorization. That is, rather than have all content come into the household and then block some of it, consumers could actively authorize what channels will be delivered to the home when they subscribe to a service. In this way, undesirable channels would never enter the household.

Another concern some may have to the digital environment is that it will destroy the integrity of programs by breaking them up into windows on the TV screen, superimposing other content or ads over the program, and letting viewers insert their comments about the program on the TV screen for all to see. In theory, digital environments will let producers and viewers have it both ways. That is, producers could still create linear programs with no windows or inserts if they wish and viewers could bring up windows and other inserts or choose to watch the program free of any interruptions to the linear integrity of a program. However, the options available to both producers and viewers will depend upon the specific design of each digital system.

Are there opportunities for more or better public service and cultural content? Clearly, the answer is yes. However, public service and cultural content will have to compete in an environment of greater choice. The near-term opportunity may be to offer theme channels that narrowly target specific audience segments. For example, there is a need for high quality children's content in early evening but public service channels with restricted capacity have used this time period for news and other content directed towards older audiences. Similarly, audiences would benefit from public service and cultural content that is multicast at different times on different channels, making the programs fit more conveniently into the schedules of busy households. ARD and the BBC in Europe as well as PBS in the U.S. are moving in this direction. 
The re-packaging of content and distribution of the same content on multiple channels raise a questions about the shelf-life for programming and the impact of digital systems on syndication revenues over time. Currently, many popular programs enjoy a long life in syndication. If distribution moves in a vertical direction wherein programs saturate the market through repetitive carriage on many channels, will this reduce the value of horizontal distribution over time through over-exposure of the programming?

Access to popular programs by distributors raises another concern. Will cable, satellite, telephone and wireless digital TV system operators be able to secure programming at reasonable rates. Fair access to content was written into U.S. legislation in 1992 and into subsequent FCC rules, but there have been many complaints that access has been denied to competitors by large companies that have both content and distribution interests $^{31}$. Similar problems have arisen in Europe ${ }^{32}$. This has been a particular problem in rights to sporting events that are so popular among the early adopters of digital services.

In the long-term, the most interesting impact of digital technology on TV channels may be to eliminate them. At some point in the future, all programming may be stored on video servers and consumers could choose from libraries with thousands of programs. This would eliminate both schedules (except for live programming) and channels. In this environment, networks might be replaced with program services that specialize in certain categories of content or compete by virtue of their brand names and the quality of their programming stock.

The appeal of Web services on television is not yet clear. Some have argued that television is a poor medium for displaying text and, further, that people will not want to 
spend long sessions getting information over TV. However, teletext has been successful in Europe and much Web content provides entertainment that suits the interests of most TV viewers. The appeal of these services may vary by region and in relation to comparative product advantages. It appears that there is a market for high-speed Web access over cable that can be displayed on TV or a PC. Web services delivered through the television signal, e.g., the vertical blanking interval (VBI) may also be popular in areas of the U.S. and Europe where telecommunication costs to access the Web are very high. HDTV may have a number of very interesting impacts on content once it is offered. The high resolution of HDTV images shows the flaws in many TV studio sets. False walls and backgrounds that are perfectly acceptable with the current TV standards appear to be flimsy and artificial on HDTV. In addition, HDTV shows skin tones, facial wrinkles and other bodily details much more sharply than conventional TV. It remains unclear whether these features combined with larger digital sets will have an impact upon the appeal of actors, politicians and others who rely on television to achieve popularity. Similarly, certain types of content may be more appealing or less appealing on high-reolution, largescreen TV.

Some have questioned whether audiences want to interact with television or do more work while watching TV, e.g., pressing buttons on a remote control that bring up text into a window on the screen. Aren't most TV viewers passive couch potatoes? There is much research to suggest that the couch potato stereotype has been overstated. Many people interact with TV content by talking about it to others and many viewers love to use remote controls ${ }^{33}$. However, the digital environment will be a frenetic experience only for 
those who wish to use it that way. For most viewers, it will simply provide more selection and control over what they watch.

\section{The Business Case For Digital Services}

The most challenging aspect of content for digital TV is trying to understand what level of revenue it might generate. Several marketplace elements are likely to interact in determining the business case for new digital services. First, there has been a long-term and gradual shift in the percentage of revenue television generates from advertisers, government and consumers: consumers pay a much larger share today compared with the $1960 \mathrm{~s}^{34}$. Second, in the cable and satellite environments, system operators currently pay for programming that they distribute (versus terrestrial network television in the U.S., where networks pay local stations to carry their content). In this sense, there is an existing pattern of distributors paying for extra channels and passing these costs along to subscribers. Third, the new digital environment will permit many new forms of pricing such as volume discounts. However, currently, many billing systems are not equiped to handle discounting such as buy three movies and receive a fourth free. Other positive factors for digital content revenue are a general increase in consumer spending for entertainment over the past decade and a shift in spending by some households away from videocassette rentals and towards pay television ${ }^{35}$.

Interacting with these revenue factors are a number of challenges and uncertainties. For example, if the amount of content is increased in a digital TV environment, will households watch more TV (currently over 7 hours per day in U.S. households)? In addition, will the concentration of audience viewing among a few channels ( 9 channels 
watched per week in an average US household; 4 channels per week for households in the U.K. ${ }^{36}$ ) change significantly? Further, will additional channels attract new advertising and increase total advertising revenue or will advertising revenue simply be spread across a wider universe of channels? This is an important issue for groups developing theme channels who want to create a new brand identity or extend an existing brand across new channels. Marketing and advertising costs for extra channels will be significant. Typically, 25 percent of a channel's total budget goes to advertising and marketing ${ }^{37}$.

Content and technology are likely to interact in a number of other ways that may affect the development of digital TV. For example, with so many new and incompatible systems being offered in the marketplace, will producers create content for each system? This would be very expensive. In the absence of a critical mass of content, will consumers have sufficient incentive to buy a new digital box or will they have to purchase more than one box to receive a critical mass of attractive content? To complicate the analysis even more, digital systems are evolving quickly and new models with advanced features are replacing older ones every 12 to 18 months, as in the case of WebTV. Content created for an earlier model may have a short shelf life or be incompatible with newer systems.

\section{What Will Happen?}

With all of the possibilities for new content and services in the digital environment, what will actually happen? New digital services reinforce an old axiom about innovations in media, i.e., advances in technology determine what new services are possible but a combination of price, regulation, consumer interest, commercial investment and marketing agreements determine what will actually happen. For example, while it is technically 
possible to offer video telephone service over digital cable systems, the complexity of the equipment configuration for the latest videophone offerings along with weak interest in such services during previous trials ${ }^{38}$ suggest that the odds of success are quite long. Similarly, many proposed new services may die on the vine because they do not attract sufficient commercial investment or because major system operators block their distribution.

It is an important time for academic researchers, industry leaders and policy makers who wish to understand the significance of digital content, help desirable services develop successfully and serve consumers. In addition to the major questions surrounding digital broadcasting such as technical standards, licenses for operators and other well-known regulatory areas, there are a number of key content issues that deserve academic, industry and government attention. These include: adult or pornographic content; parental controls over services; the uses of program guides; fair access to content by system operators; limitations if any on the digital insertion of ads; and the potential for digital manipulation of news content.

\section{Notes And References}

\footnotetext{
1 J. Brinkley, Defining Vision: The Battle for the Future of Television, Harcourt Brace and Company, New York, 1997.

2 A. Pollack, Japan Says It Will Move Up Introduction of Digital Television By A Few Years,' The New York Times, March 11, 1997, p. D6.

${ }^{3} \mathrm{~K}$. Pope and M. Robichaux, 'Waiting For HDTV? Don't Go Dumping Your

Old Set Just Yet,' The Wall Street Journal, September 12, 1997, p. A-1.

4 J. Brinkley, 'Executives Seeking Ways To Make Conventional TV Look Better In A High-Definition World,' Cybertimes, December 15, 1997.

5 E. Thomas, 'Digital Hollywood: Box Office Bust,' MSNBC: Commerce (MSNBC.Com/News), November 6, 1997.

6 J. Alter, 'What's On TV?' Media Studies Journal, Volume 8, Number 1, Winter 1994, pp. 73-79.
} 
7 S. Sreenivasan, 'Newscasts In Tagalog And Songs In Gaelic,' The New York Times, September 8, 1997, p. D11.

8 J. Cooper, 'Digital Dancing,' CableVision, October 6, 1997, p. 35.

9 C. Harper, 'More Digital Delays In Germany,' Cable World, September 9, 1997, pp. 39-40.

10 M. Reynolds and A. Breznick, 'MTV, Lifetime Lining Up For The Digital TV Parade,' Cable World, December 1, 1997, p. 1.

11 T. Hearn and L. Moss, 'The Mouse Eyes Digital,' Multichannel News, November 24, 1997, p. 1 .

12 ' 'Grabbing A Slice of Sky's Pie,' The Economist, October 4, 1997, pp. 70-73.

13 Cited in N. Negroponte, Being Digital, Alfred Knopf Publishers, New York, 1995, p. 127.

14 ', 'Entertained By Commercials,' American Demographics, Novermber 1997, p. 41.

15 P.Patton, 'Screens Swarm With Logos, Crawls, and Tickers as TV Chases The Internet,' The New York Times, October 30, 1997, p. F2.

${ }^{16}$ M. Chakraborty, 'VOD: Looking Ahead,' Cable And Satellite Europe, August, 1997, pp. 30-33.

${ }_{17}$ W. Bulkeley and J. Wilke, 'Can The Exalted Vision Become A Reality,' The Wall Street Journal, October 14, 1993, p. B1.

18 K. Mitchell, 'Some Boffo Bell Atlantic Buy Rates,' Cable World, March 25, 1996, p. 20.

19 H. Jessel, 'Warning Flags Over VOD,' Broadcasting And Cable, March 20,1995, p. 33.

20 M. Levine, 'Competition May Put VOD Back On MSO Track,' Multichannel News, December 8, 1997, p. 192.

$21 \mathrm{~J}$. Barthold, 'Looking For VOD? DIVA Says It's Got The Ticket,' Cable World, December 1, 1997, p. 12.

${ }^{22}$,' 'The Business of PPV,' Cable And Satellite Europe, October, 1997, pp. 21-22.

3 J. Carey, 'Winky Dink To Stargazer: Five Decades of Interactive Television,' paper presented at UnivEd Interactive TV Conference, University of Edinburgh, September, 1996.

24 , ITV News, University of Edinburg,

WWW.ITVnews.com/research/digworld.htm, January, 1998.

${ }^{25}$ F. Williams, The New Telecommunications, The Free Press, New York, 1991.

26 B. Haring, 'Video On The Net Is Snapping Into Focus,' USA Today, November 26, 1997, p. 4D.

27 E. Thomas, 'More Ways To Get Web On TV,' MSNBC, November 4, 1997, MSNBC.Com

$28 \mathrm{~J}$. Barthold, 'Exactly what Is Interactive TV?' Cable World, December 15, 1997, p. 58 .

29 ' 'TV Stations Urged To Go Interactive,' Broadcasting And Cable, December 20, 1993, p. 50 .

30 V. Vittore, 'The New Video Mix,' Telephony, December 8, 1997, pp. 2432 .

31 E. Glick, 'Program Access,' Cablevision, December 8, 1997, p. 28.

32 R. Frank and M. Rose, 'A Massive Investment in British Cable TV Sours For U.S. Firms,' The Wall Street Journal, December 17, 1997, p. A1.

33 R. Bellamy and J. Walker, Television and the Remote Control: Grazing on a Vast Wasteland, The Guilford Press, New York, 1996.

${ }^{34}$ L. Bogart, 'Highway To The Stars or Road To Nowhere, Media Studies Journal, Volume 8, Number 1, Winter, 1994, pp. 1-15. 
35 , Communication Industry Report, Veronis and Suhler, New York, 1997 .

36 R. Frank and M. Rose, op. cit., p. A1.

37 K. Mitchell, 'The State of Pay TV,' Cable World, October 13, 1997, pp. 22-30.

A.M. Noll and J. Woods, 'The Use Of Picturephone Service In A Hospital,' Telecommunications Policy, March, 1979, pp. 29-36. 